\title{
Approaches in Health Human Resource Forecasting: A Roadmap for Improvement
}

\author{
Sima Rafiei ${ }^{1}$, Rafat Mohebbifar ${ }^{2}$, Fariba Hashemi $^{3}$, Mohammad Ranjbar Ezzatabadi ${ }^{4}$, Fereshteh Farzianpour ${ }^{5}$
}

${ }^{1}$ Ph.D. of Healthcare Management, Assistant Professor, Department of Health Management, School of Health, Qazvin University of Medical Sciences, Qazvin, Iran

${ }^{2}$ Ph.D. of Healthcare Management, Associate Professor, Department of Health Management, School of Health, Qazvin University of Medical Sciences, Qazvin, Iran

${ }^{3}$ M.Sc. in Nursing, Department of Operating Room, Faculty of Para medicine, Qazvin University of Medical Sciences, Qazvin, Iran

${ }^{4}$ Ph.D. of Health Policy, Health policy Research Center, Shahid Sadoughi University of Medical Sciences, Yazd, Iran

${ }^{5}$ Ph.D. of Healthcare Management, Associate Professor, Department of Health Management and Economics, School of Public Health, Tehran University of Medical Sciences, Tehran, Iran

Type of article: Systematic review

\begin{abstract}
Introduction: Forecasting the demand and supply of health manpower in an accurate manner makes appropriate planning possible. The aim of this paper was to review approaches and methods for health manpower forecasting and consequently propose the features that improve the effectiveness of this important process of health manpower planning.

Methods: A literature review was conducted for studies published in English from 1990-2014 using Pub Med, Science Direct, Pro Quest, and Google Scholar databases. Review articles, qualitative studies, retrospective and prospective studies describing or applying various types of forecasting approaches and methods in health manpower forecasting were included in the review. The authors designed an extraction data sheet based on study questions to collect data on studies' references, designs, and types of forecasting approaches, whether discussed or applied, with their strengths and weaknesses

Results: Forty studies were included in the review. As a result, two main categories of approaches (conceptual and analytical) for health manpower forecasting were identified. Each approach had several strengths and weaknesses. As a whole, most of them were faced with some challenges, such as being static and unable to capture dynamic variables in manpower forecasting and causal relationships. They also lacked the capacity to benefit from scenario making to assist policy makers in effective decision making.

Conclusions: An effective forecasting approach is supposed to resolve all the deficits that exist in current approaches and meet the key features found in the literature in order to develop an open system and a dynamic and comprehensive method necessary for today complex health care systems.
\end{abstract}

Keywords: Forecasting approach, Predict, Demand, Supply, Health human resources

\section{Introduction}

Health care systems are intensively dependent on human resources worldwide. Imbalance in health manpower supply and demand will have a negative effect on the quality of health services and impose high expenditures on health care systems. An oversupply may increase health care costs of the health system through provider-induced demand, while insufficient supply may cause health needs of the population to be unmet or provided with lower quality (1-3). Therefore, one of the major concerns of policy makers in health sectors is to avoid the imbalances between supply and demand of health care personnel. To have a well-functioning health care system, it is inevitable

\section{Corresponding author:}

Fereshteh Farzianpour, Department of Health Management and Economics, School of Public Health, Tehran University of Medical Sciences, Tehran, Iran. Tel: +98.2188989129, Email: farzianp@sina.tums.ac.ir

Received: January 10, 2016, Accepted: March 30, 2016, Published: September 2016

iThenticate screening: March 12, 2016, English editing: May 17, 2016, Quality control: July 28, 2016

(C) 2016 The Authors. This is an open access article under the terms of the Creative Commons Attribution-NonCommercialNoDerivs License, which permits use and distribution in any medium, provided the original work is properly cited, the use is non-commercial and no modifications or adaptations are made. 
to have adequate number with proper performance of health manpower (1). The aim is to ensure that health manpower is available and ready to provide services in "the right place at the right time with the right skills" $(2,3)$. Health human resource planning involves reviewing the current supply of manpower resources, forecasting their future requirements (demand) and availability (supply), and developing strategies to ensure an appropriate balance between supply of and demand for manpower. After defining an appropriate number of health manpower needed to meet requirements for health services, it is necessary to develop some policies to keep supply and demand of manpower in balance (4-6).

To address an appropriate number of health manpower needed, there are several forecasting methods that various strengths and weaknesses (4-26). The majority is based on the supply-based approach (manpower-population ratio) for the reason of data availability. This approach with valid data on providers and population statistics can be helpful for estimating the manpower requirement for an entire country and a number of various health manpower categories. In other cases, service utilization rates were more applicable and used for estimating health manpower requirement in private sector or health systems with passive government. This approach computes utilization rate of health services in different populations. Unlike the manpower-population ratio, data availability is not a strengthening point of this approach, but similar to manpower-population ratio, the demand-based approach masks major regional imbalances. Both approaches also ignore the effects that manpower planning might have on health system outcomes and the population's health status. The complexity and dynamic nature of health systems are other features mostly ignored in these two approaches $(32,39)$. They generally fail to consider real health needs of the population in manpower planning, pay little attention to demand and need factors, and are limited to demographic characteristics in estimating future requirements for health manpower. For a health care system with a large public sector active in care delivery, there are two types of useful approaches that can be applied, i.e, needs-based and the health services target approach. Planning for supply and demand of manpower consistent with regional health needs of the population is essential in these approaches. The needs-based approach seems to have a reasonable logic, because, unlike the demand-based approach, it does not consider the current level or distribution of health manpower to be necessarily adequate; instead, it emphasizes the relative health needs of the population. The health service target approach matches the supply of health manpower with the health services mentioned as a target to be met for a particular population. This is a politically-appealing approach that makes manpower planning possible at the local levels. Although there are strengths noted above for these two approaches, there are also a number of shortcomings. One of them, similar to the supply and demand-based approach, is the ignorance of the intricacy and dynamic nature of the health system and the many factors that have important roles in planning health manpower. Benchmarking is the last approach, and it relies on international or inter-homogenous health system indicators to identify health manpower requirements. Although it is easy to apply and compare manpower ratios in regions with similar health system characteristics, but, the same as all of the approaches mentioned above, it also has an important deficit. Most of them do not have the ability to capture all key factors that affect the demand and supply of health manpower. To propose a single comprehensive approach incorporating the strong points of the other methods, a comprehensive review of existing approaches must be conducted to determine their advantages and limitations. In this way, the challenges of such models would be analyzed to determine possible roadmaps for improvement.

\section{Material and Methods}

\subsection{Setting}

The English language databases of Pub Med, Science Direct, Google Scholar, and Pro Quest were searched to find articles related to the subject of this study. Reports also were investigated by searching the websites of the World Health Organization (WHO) and international professional associations related to workforce research. Examples for such associations include the Canadian Nurses Association and the Association of American Medical Colleges.

\subsection{Inclusion and Exclusion Criteria}

We chose a time period from January 1, 1990, to December 30, 2014, for the search process of the study. Similar search terms, including "forecasting approaches OR forecasting methods OR predict OR project" AND "demand OR supply" AND "health manpower OR health workforce OR health human resources OR health care professionals" were used for all databases. The search was restricted to articles and reports with full text accessibility published in English. Studies including the non-clinical workforce were not incorporated in the review. Also, we did not consider studies conducted in a format of books or quantitative surveys. 


\subsection{Quality Assessment}

Existence of valid instruments and presence of inclusion and exclusion criteria were checked to ensure the quality of the study. Data were based on the search results identifying 960 articles from which 40 studies ultimately were selected after applying the exclusion criteria.

\subsection{Data collection}

The authors designed an extraction data sheet based on the study questions. This form was used to collect data on studies' references, countries, designs, and types of forecasting approaches, whether discussed or applied with their strengths and weaknesses. For each study, two authors (SR and MA) completed the sheets independently. Any disagreement was solved through consensus.

\section{Results}

In an initial search, 960 publications were found. Screening documents based on their titles and abstracts revealed 570 duplicates or non-relevant studies. After reviewing the full texts of the remaining studies, 317 of them were excluded because of they were not consistent with the inclusion criteria. Among the 317 studies, 175 did not meet our criteria for study subject, 18 were not compatible with the inclusion criteria of study design, 65 studied forecasting approaches among non-health workforce, and 59 provided no data on strengths and weaknesses of the forecasting approaches. Thirty-five documents also were removed due to similarity in method and data provided. Considering the reference lists of the remaining studies led to two additional publications that met our inclusion criteria and were not duplicates of the other studies. Thus, 40 studies were included in the review both from developed and developing countries.

\subsection{An effective method in health manpower forecasting}

To date, most of the health manpower forecasting methods have not considered the complete number of dynamic variables in manpower forecasting and their causal relationships. They also lack the capacity to benefit from scenario making to assist planners and policy makers in effective decision making (27). Modern forecasting approaches must resolve all of the deficits that exist in the current approaches and meet the key features found in the literature in order to develop an open system, dynamic, and comprehensive method necessary for today's complex health care systems $(17,28,29)$. Some of the key features are 1) taking into account the full range of dynamic variables affecting manpower supply and demand, 2) considering their inherent uncertainty and complex interactions, 3) having a system-level perspective with a dynamic approach, and 4) having the ability to create scenarios that are useful for policy-making purposes (27). Our study recommends using a dynamic model that has the following features $(1,22,27)$ :

3.1.1. Incorporating all relative factors with dominant effect on manpower supply and demand:

There are several factors that have dominant effect on manpower supply and demand (6). In order to have a comprehensive conceptual approach, as many of these factors as possible should be included. Reviewing the literature provided a number of these factors. Providing high-quality, longitudinal data around the key factors is essential in making a valid and reliable manpower forecast $(17,21,27,29-32)$.

3.1.2. Monitoring trends of these factors over time:

In most cases, models lack a complete number of dynamic variables and the possibility to attain high-quality data to investigate their trends after a while $(1,22,27)$. Considering the impact of emerging technologies, socio-cultural evolution, economic changes, political incentives, demographic and epidemiological trends on health services requirement or health system capacity to meet these requirements are the examples addressing the importance of monitoring trends in affecting factors over time (17, 28, 30, 33).

3.1.3. Considering complex interactions among these factors:

Taking into account complex interactions among variables affecting manpower supply and demand is another important feature. For an instance, population size and demographic, their average income and educational level, insurance coverage, incidence of diseases, and service utilization rates are among the factors affecting demand for health manpower. Although all of these factors affect the demand for manpower, there also are several interrelationships between the affecting factors. Population size and demographics, their average income and educational level, and insurance coverage, for example, can affect the utilization rate for manpower services in a population. Clarifying all possible interactions among variables will identify the complex nature of manpower modeling (34-37). 3.1.4. Applying 'what-if' scenarios is helpful for policy making purposes:

The ability of the model to check 'what-if' scenarios is another important factor to be considered. This feature allows planners and policy makers to explore the consequences of the alternative policies used in planning manpower, and it provides a means of assisting them to make effective decisions. The model's success in proposing 
useful scenarios is dependent on the quality of the data and the proper selection of the variables for the model in a way to reflect the entire system $(17,38)$. Sensitivity analysis allows policy makers and planners to make different estimates of the required services and, consequently, plan for the number of manpower required $(17,34,35,37,39)$. A system dynamic modeling approach can cover the above features. It has the ability to take into account a complete number of dynamic variables in manpower planning and to consider both quantitative and qualitative aspects. The model can be useful in better policy making for manpower supply and demand by taking into account the complexity of different contextual variables and a combination of various perspectives (17). The model also can be used for forecasting purposes in long periods of time and large number of population. The ability of the model in responding to 'what-if' scenarios can help planners and policy makers in making decisions more effectively in manpower planning $(34-37,39)$. Table 1 shows the differences between the old and modern approaches in planning health manpower (40) as compared to system dynamic (SD) modeling.

Table 1. Differences between old and modern approaches in health manpower planning comparing to SD model

\begin{tabular}{|l|l|l|}
\hline Old approaches & Modern approaches & SD model \\
\hline Static modeling & Dynamic modeling & $\begin{array}{l}\text { Dynamic nature of variables } \\
\text { considered } \\
\text { Complex interactions among } \\
\text { variables considered }\end{array}$ \\
\hline $\begin{array}{l}\text { Model specifications fixed in } \\
\text { time }\end{array}$ & Self-learning and self-correcting & $\begin{array}{l}\text { Model specifications not constant in } \\
\text { time }\end{array}$ \\
\hline $\begin{array}{l}\text { Limited variables included } \\
\text { Limited feedback on } \\
\text { projections }\end{array}$ & All complex variables included & All complex variables included \\
\hline No national database & Continuous validation process & $\begin{array}{l}\text { Feedback, time lags and delays } \\
\text { considered }\end{array}$ \\
\hline No minimum dataset & National database & National database \\
\hline $\begin{array}{l}\text { Short term forecasting is } \\
\text { possible }\end{array}$ & Minimum dataset for manpower & $\begin{array}{l}\text { Medium to long term forecasting is } \\
\text { possible }\end{array}$ \\
\hline $\begin{array}{l}\text { Quantitative data are able to } \\
\text { be modeled }\end{array}$ & $\begin{array}{l}\text { Both quantitative and qualitative data are } \\
\text { able to be modeled }\end{array}$ & $\begin{array}{l}\text { Qualitative data are able to be } \\
\text { modeled }\end{array}$ \\
\hline
\end{tabular}

\section{Discussion}

This paper reviews available forecasting methods for health manpower and consequently proposes the features that improve the effectiveness of health manpower forecasting. Several conceptual approaches were introduced to forecast health manpower supply and demand (4-26, 28). Most of them were based on the supply-based approach (manpower-population ratio) for the reason of data availability. This approach with valid data on providers and population statistics can be helpful for estimating manpower requirement for an entire country and for several health manpower categories $(6,8,12,14,16)$. In other cases, service utilization rates were more applicable and used for estimating health manpower requirement in the private sector or health systems with passive government. This approach computes utilization rate of health services in different populations. Unlike the manpower-population ratio, data availability is not a strengthening point of this approach, but, similar to the manpower-population ratio, the demand-based approach masks major regional imbalances. Both approaches also ignore the effects that manpower planning might have on health system outcomes and the population's health status. The complex and dynamic natures of health systems are other features that mostly are ignored in these two approaches $(17,22)$. They generally fail to consider the real health needs of the population in manpower planning, they pay little attention to demand and need factors, and they are limited to demographic characteristics in estimating future requirements for health manpower $(4-7,9,12,13,18,20,26)$.

For a health care system with a large public sector active in care delivery, there are two types of approaches mostly useful to be applied, i.e., needs-based and health services target approach. Planning for supply and demand of manpower that is consistent with regional health needs of the population is essential in these approaches. The needsbased approach seems to be reasonably logical because, unlike the demand-based approach, it does not consider the current level or distribution of health manpower to be necessarily adequate; instead it emphasizes the relative health needs of the population $(5,8,11,15,19,23,24,28)$. The health service target approach matches health manpower supply with health services mentioned as a target to be met for a particular population. This is a politically-appealing 
approach that makes manpower planning possible at the local levels $(8,12,26)$. Although strengths are noted above for these two approaches, there also are several shortcomings. One of them, similar to the supply and demand-based approach, is ignorance of the intricacy and dynamic nature of health systems and the several factors that have important roles in health manpower planning $(13,17,18,22,26,27)$. Benchmarking is the last approach, and it relies on international or inter-homogenous health system indicators to identify health manpower requirements. Although it is easy to apply and compares manpower ratios in regions with similar health system characteristics, but, the same as all of the approaches mentioned above, it also has an important deficit (10). None of the five approaches has the ability to capture all key factors affecting demand and supply of health manpower, e.g., economic, sociocultural, political, technological, service utilization rates, incidence of disease, and other factors influencing health manpower planning. They also lack the ability to consider the dynamic interactions among the full range of variables and to make possible scenarios in response to 'what-if' questions $(13,18,26,28)$. We recommend developing a comprehensive health manpower model with a conceptual framework including as many of these factors as possible. Population demography, technology development, accessibility to health services, service utilization, incidents of diseases, economic, social, political factors and manpower work pattern are among the important elements that must be considered in a manpower planning model $(2,17,21,27,31,32)$. These influencing variables and their causal effects must be clearly identified (26). This open system and dynamic modeling is a feature mostly ignored in the existing literature. Including as many as possible of the factors related to the five mentioned approaches accompanied with high-quality data will equip our model to be optimally effective in estimating health manpower requirements $(17,28)$.

\section{Conclusions}

Effective health manpower planning is critical to guarantee adequate number of staff available and consequently good quality and resourceful health care services delivered to the population. To address an appropriate number of health manpower, there are a number of forecasting approaches and methods with their own strengths and weaknesses. Since there is always a challenge for selecting an appropriate approach, this paper attempted to provide an evidence-based framework to facilitate the process. The results of this study suggest that future forecasting methods should benefit from advantages of current approaches and overcome some of their main limitations. Applying a method that incorporates a wide range of factors affecting supply and demand, facilitates the collection of good quality data, monitors changing trends over time, considers the uncertainty of health systems, and has a dynamic approach is proposed as an improvement roadmap for future forecasting. System dynamics covers the above features and has the ability to take into account a complete number of dynamic variables in manpower planning and consider both quantitative and qualitative aspects. The model also will be useful in making better policies for manpower supply and demand and designing trustworthy policies for their recruitment, distribution, training capacity, and attrition purposes. Therefore, it is recommended that this method be applied in projecting the number of required workforce in today's complex health care systems and to analyze the results of health manpower planning.

\section{Acknowledgments:}

The paper is the result of a research project funded by Tehran University of Medical Sciences. We acknowledge Dr. Alaeddini, Dr. Farzadi, and Dr. Sedaghat, who contributed to organizing the structure of the manuscript.

\section{Conflict of Interest:}

There is no conflict of interest to be declared.

\section{Authors' contributions:}

All authors contributed to this project and article equally. All authors read and approved the final manuscript.

\section{References:}

1) Roberfroid D, Stordeur S, Camberlin C, Van de Voorde C, Vrijens F, Leonard C. Physician workforce supply in Belgium: Current situation and challenges. Health Services Research (HSR). Brussels: Belgian Health Care Knowledge Centre (KCE); 2008. KCE reports C (D/2006/10.273/).

2) Birch S. Health human resource planning for the new millennium: inputs in the production of health, illness, and recovery in populations. Can J Nursing Res. 2002; 33: 109-14. PMID: 11998188.

3) Stokker JH, Gillian $\mathrm{H}$. The right person, in the right job, with the right skills, at the right time. A workforce planning model that goes beyond metrics. Library Manag. 2009; 30(8): 561-71. doi: 10.1108/01435120911006520. 
4) Anderson GF, Han KC, Miller RH, Johns ME. A comparison of three methods for estimating the requirements for medical specialists: the case of otolaryngologists. Health Serv Res. 1997; 32: 139-53. PMID: 9180613, PMCID: PMC1070178.

5) Centre CLaB. Canada's Physician Workforce: Occupational Human Resources Data Assessment and Trend Analysis Executive Summary. Ottawa, Canada: Canadian Policy Research Networks; 2000.

6) Chan B. From perceived surplus to perceived shortage: what happened to Canada's physician workforce in the 1990's? Ottawa, Ontario: Canadian Institute for Health Information; 2002.

7) Dreesch N, Dolea C, Dal Poz MR, Goubarev A, Adams O, Aregawi M. An approach to estimating human resource requirements to achieve the Millennium Development Goals. Health Policy Plan. 2005; 20 : 267 76. doi: 10.1093/heapol/czi036.

8) Dussault GB, J. Sermeus, W. Padaiga, Z. Assessing future health workforce needs-Investing in Europe's health workforce of tomorrow: Scope for innovation and collaboration. Geneva: European Observatory on Health Systems and Policies; 2010

9) Gavel P. Medical workforce planning in Australia: process, methodology and technical issues. Cah Sociol Demogr Med. 2004; 44(1): 7-42. PMID: 15146657.

10) Goodman DC, Fisher ES, Bubolz TA, Mohr JE, Poage JF, Wennberg JE. Benchmarking the US physician workforce. An alternative to needs-based or demand-based planning. JAMA. 1996; 276(22): 1811-7. doi: 10.1001/jama.1996.03540220035027. PMID: 8946901.

11) Katz A, Bogdanovic B, Ekuma O, Soodeen RA, Chateau D, Burnett C. Physician resource projection models. Manitoba: Manitoba center for health policy, Department of community health sciences, Faculty of medicine, University of Manitoba; 2009.

12) Keet MP, Henley LD, Power HM, Heese HV. Medical manpower-South African situation models for planning and recommendations. S Afr Med J. 1990; 78(10): 591-7. PMID: 2247793.

13) Lavis JN, Birch S. The answer is ..., now what was the question? Applying alternative approaches to estimating nurse requirements. Can J Nurs Adm. 1997; 10(1): 24-44. PMID: 9086965.

14) Lee PP, Jackson CA, Relles DA. Demand-based assessment of workforce requirements for orthopedic services. J Bone Joint Surg Am. 1998; 80(3): 313-26. PMID: 9531197.

15) Markham B, Birch S. Back to the future: A framework for estimating health care human resource requirements. Can J Nurs Adm. 1997; 10(1): 7-23. PMID: 9086964.

16) Lurie JD, Goodman DC, Wennberg JE. Benchmarking future generalist workforce. Eff Clin Pract. 2002; 5(2): 58-66. PMID: 11990213.

17) Murphy GT, O’ Brien-Pallas L. How Do Health Human Resources Policies and Practices Inhibit Change? A Plan for the Future. Canada: Commission on the future of Health Care in Canada; 2002.

18) O'Brien-Pallas L, Baumann A, Birch S, Murphy GT. Health human resource planning in home care: How to approach it--That is the question. Healthc Pap. 2000; 1(4): 53-9. doi: 10.12927/hcpap..17351. PMID: 12811173.

19) O’Brien-Pallas L, Baumann A, Donner G, Lochhass GJ, Luba M, Lakats L, et al. Health human resources: An analysis of forecasting models. Ontario, Canada: Canadian Nurses Association; 1998.

20) Organization. WH. Models and Tools for Health Workforce Planning and Projections. Geneva: Human Resources for Health Observer, World Health Organization; 2010.

21) Rizza RA, Vigersky RA, Rodbard HW, Ladenson PW, Young WF, Surks MI, et al. A model to determine workforce needs for endocrinologists in the United States until 2020. J Clin Endocrinol Metab. 2003; 88(5): 1979-87. doi: 10.1210/jc.2002-021288. PMID: 12727941.

22) Roberfroid D, Leonard C, Stordeur S. Physician supply forecast: better than peering in a crystal ball. Hum Resour Health. 2009; 7(10). doi: 10.1186/1478-4491-7-10. PMID: 19216772.

23) Roos NP, Bradley JE, Fransoo R, Shanahan M. How many physicians does Canada need to care for our aging population? CMAJ. 1998; 158(10): 1275-84. PMID: 9614820, PMCID: PMC1229321.

24) Roos NP, Fransoo R, Bogdanovic B, Carriere KC, Frohlich N, Friesen D, et al. Needs based planning for generalist physicians. Med Care. 1999; 37(6): 206-28. doi: 10.1097/00005650-199906001-00017. PMID: 10409010.

25) Salsberg E. California Physician Workforce: supply and demand through 2015. New York: The center for health workforce studies, University of Albany, State University of New york; 2004.

26) Scott A, Sivey P, Joyce C, Schofield D, Davies Ph. Alternative approaches to health workforce planning. Australia: School of Population Health, National Health Workforce Taskforce, University of Queensland; 2011. 
27) Joyce CM, Mc Neil J, Stoelwinder JU. Time for a new approach to medical workforce planning. Med J Aust. 2004; 180: 343-6. PMID: 15059057.

28) Solutions. DCfH. Better health care worker demand projections: A twenty first century approach: Bipartisan Policy Center; 2013.

29) Ono T, Lafortune G, Schoenstein M. Health Workforce Planning in OECD Countries: A Review of 26 Projection Models from 18 Countries; 2013. Report No.: 62. doi: 10.1787/18152015.

30) Birch S, Kephart G, Murphy GT, O'Brien-Pallas L, Alder R, MacKenzie A. Health human resources planning and the production of health: Development of an analytical framework for needs-based health human resources planning. J Public Health Manag Pract. 2009; 15(6 Suppl): S56-61. doi: 10.1097/PHH.0b013e3181b1ec0e. PMID: 19829233.

31) Curson J, editor. Physician workforce planning: what have we learned? Lessons for planning medical school capacity and IMG policies. 7th International Medical Workforce Conference; 2003 Sep 11-14; UK. Oxford.

32) Dill J, Salsberg E. The Complexities of Physician Supply and Demand: Projections through 2025: Association of American Medical Colleges, Center for Workforce Studies; 2008 Contract No: Document Number.

33) Greenberg L, Cultice JM. Forecasting the need for physicians in the United States: the Health Resources and Services Administration's physician requirements model. Health Serv Res. 1997; 31: 723-37. PMCID: PMC1070155.

34) Aburawi I, Hafeez K. Managing dynamics of human resource and knowledge management in organizations through system dynamics modeling. Int J Sci Tech Automatic Control Eng. 2009; 3(2): 1108-25.

35) Brailsford SC, editor. System dynamics: what's in it for health care simulation modelers. Simulation Conference; 2008; UK. University of Southampton. doi: 10.1109/WSC.2008.4736227.

36) Morecroft J, Robinson S, editors. Comparing Discrete- Event Simulation and System Dynamics: Modeling a Fishery. Operational Research Society Simulation; 2006; Birmingham, UK. doi: 10.1002/9781118762745.

37) Mutingi M. System dynamics of manpower planning strategies under various demand scenarios. Manag Sci Letters. 2012; 2: 2689-98. doi: 10.5267/j.msl.2012.09.027.

38) O'Brien-Pallas L, Birch S, Baumann A, Murphy GT. Integrating workforce planning, human resources and service planning. Geneva, Switzerland: WHO, Department of organization of health services delivery; 2001. Available from: www.who.int/hrh/documents/en/Integrating_workforce.pdf

39) Park S, Lee SM, Yoon SN, Yeon S. A dynamic manpower forecasting model for the information security industry. Indust Manag Data Systems. 2008; 108(3): 368-84. doi: 10.1108/02635570810858778.

40) Solutions. DCfH. The future of our health professional workforce: the care for a comprehensive national strategy: Bipartisan Policy Center; 2013. 